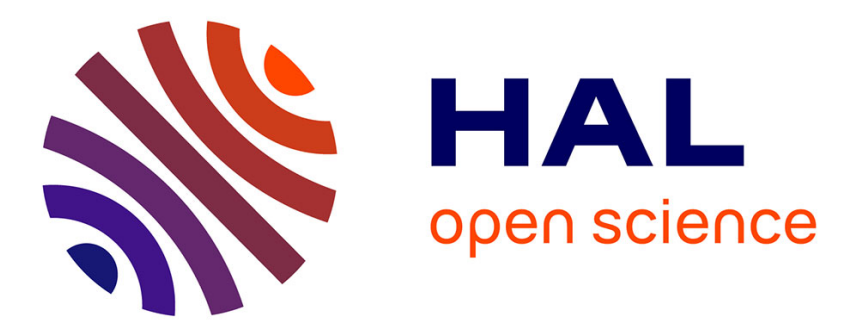

\title{
Unexpected Alternated Radical Copolymerization of Vinylidene Cyanide with a Vinyl Ether for Superhydrophobic and Highly Oleophobic Films
}

\author{
Ahmed Meskini, Mustapha Raihane, Bruno Ameduri
}

\section{To cite this version:}

Ahmed Meskini, Mustapha Raihane, Bruno Ameduri. Unexpected Alternated Radical Copolymerization of Vinylidene Cyanide with a Vinyl Ether for Superhydrophobic and Highly Oleophobic Films. Macromolecules, 2009, 42, pp.3532-3539. 10.1021/ma9002165 . hal-00379244

\section{HAL Id: hal-00379244 https://hal.science/hal-00379244}

Submitted on 28 Apr 2009

HAL is a multi-disciplinary open access archive for the deposit and dissemination of scientific research documents, whether they are published or not. The documents may come from teaching and research institutions in France or abroad, or from public or private research centers.
L'archive ouverte pluridisciplinaire HAL, est destinée au dépôt et à la diffusion de documents scientifiques de niveau recherche, publiés ou non, émanant des établissements d'enseignement et de recherche français ou étrangers, des laboratoires publics ou privés. 


\title{
Unexpected Alternated Radical Copolymerization of Vinylidene
} cyanide with a Vinyl ether for Superhydrophobic and Highly Oleophobic Films

\author{
Ahmed Meskini, Mustapha Raihane \\ Laboratoire de Chimie Bioorganique et Macromoléculaire - Faculté des Sciences et \\ Techniques - Avenue Abdelkrim Khattabi - BP 549, 40000 Marrakech (Morocco)

\section{Bruno Ameduri*} \\ Engineering and Macromolecular Architectures, Institut Charles Gerhardt - UMR (CNRS) \\ 5253- Ecole Nationale Supérieure de Chimie de Montpellier - 8 Rue Ecole Normale, 34296 \\ Montpellier Cedex 5 (France)
}

* To whom correspondence should be addressed. E-mail addresses: bruno.ameduri@enscm.fr

Dedicated to Prof. Bernard BOUTEVIN for his $60^{\text {th }}$ birthday. 


\title{
Unexpected Alternated Radical Copolymerization of Vinylidene
}

cyanide with a Vinyl ether for Superhydrophobic and Highly

\section{Oleophobic Films}

\begin{abstract}
Ahmed Meskini, Mustapha Raihane
Laboratoire de Chimie Bioorganique et Macromoléculaire - Faculté des Sciences et Techniques - Avenue Abdelkrim Khattabi - BP 549, 40000 Marrakech (Morocco)
\end{abstract}

\section{Bruno Ameduri*}

Engineering and Macromolecular Architectures, Institut Charles Gerhardt - UMR (CNRS) 5253- Ecole Nationale Supérieure de Chimie de Montpellier - 8 Rue Ecole Normale, 34296 Montpellier Cedex 5 (France)

\section{Abstract}

The synthesis and the characterization of original copolymers based on vinylidene cyanide (VCN) and $1 \mathrm{H}, 1 \mathrm{H}, 2 \mathrm{H}, 2 \mathrm{H}$-perfluorodecyl vinyl ether (FAVE8) are presented. While VCN is known to be very reactive in radical homopolymerization in contrast to the vinyl ether which does not homopolymerize, the radical copolymerization of VCN with FAVE8 unexpectedly led to alternating poly(VCN-alt-FAVE8) copolymers. Seven radical copolymerization reactions were investigated with $[\mathrm{VCN}]_{0} /[\mathrm{FAVE} 8]_{0}$ percent molar ratios ranging between $15 / 85$ and 80/20. The copolymer compositions of these copolymers were assessed by elemental analyses and showed $32 \mathrm{~mol}$. \% (in one case only) to $56 \mathrm{~mol}$ \% of VCN (ca. 50 mol $\%$ in most cases). From the monomer - polymer copolymerization curve, the FinemanRoss and Kelen-Tüdos laws enabled to assess the reactivity ratios $\left(r_{\mathrm{VCN}}=r_{12}=0.08 \pm 0.01\right.$; $\mathrm{r}_{\mathrm{FAVE} 8}=\mathrm{r}_{21}=0.07 \pm 0.01$ at $75^{\circ} \mathrm{C}$ ) while the Revised Patterns Scheme led to $\mathrm{r}_{12}=2.7 \times 10^{-3}$ and $\mathrm{r}_{21}=4.0 \times 10^{-6}$ suggesting an alternating tendency of that radical copolymerization. Thermogravimetric analysis of these copolymers showed exceptional thermal stability, the 
thermal degradation starting from $350{ }^{\circ} \mathrm{C}$ under air. Original films processed from these poly(VCN-alt-FAVE8) copolymers exhibit superhydrophobic and highly oleophobic characters as evidenced by high water and diiodomethane contact angles of $168 \pm 3^{\circ}$ and 135 $\pm 3^{\circ}$, respectively. These interesting properties make them candidate for some coating applications. 


\section{Introduction}

Polymers containing polar substituents including halogen and cyano groups are of interest in the development of advanced electrical and optical materials because of the large dipole moment expected from the polar substituents. ${ }^{1}$ Nonlinear optical, piezoelectric, and pyroelectric properties have been observed in the polymers. ${ }^{2}$ Vinylidene cyanide (VCN) has often been employed in the preparation of high polar polymers as a useful starting monomer. $^{3,4}$ However, homopolymer of VCN is unstable due to chain scission by atmospheric moisture even at ambient temperature and therefore rather impractical. ${ }^{3}$ Thus, the incorporation of VCN unit into a polymer has been attempted by its copolymerization with other various vinyl and diene monomers. ${ }^{4}$ Interestingly, the study of reactivity ratios of these copolymers shows a stronger tendency to form $1: 1$ alternating copolymers. ${ }^{5}$ Their mechanical properties have also been studied. ${ }^{6}$ Radical copolymerizations of VCN with vinyl ethers ${ }^{7}$ such as vinyl isobutyl ether, butoxyethyl vinyl ether and ethyl vinyl ether have also been carried out but no copolymers were found. New applications of VCN were found by Miyata et al. ${ }^{8,9}$ or from the NASA, ${ }^{10}$ and these authors observed piezoelectric properties of the amorphous poly(VCN-co-VAc) copolymer (where VAc stands for vinyl acetate). Therefore, studies which include the copolymerization reactions of $\mathrm{VCN}$ with various monomers have been of growing relevance in the last years to study their microstructures and their electric properties. Vinylidene cyanide has been copolymerized with various monomers such as styrene, ${ }^{11}$ vinyl benzoate, ${ }^{5,11}$ methyl methacrylate, ${ }^{12}$ isopropenyl acetate, vinyl pivalate, vinyl formiate, vinyl hexanoate, $\alpha$-methylstyrene, ${ }^{13-15}$ substituted styrenes, ${ }^{16,17}$ vinyl esters of fatty acids ${ }^{18}$ and vinyl acetate. ${ }^{5,19}$ All these copolymerizations have generated alternating copolymers endowed with high $\mathrm{T}_{\mathrm{g}} \mathrm{S}$, and their microstructures have been characterized by ${ }^{13} \mathrm{C} \mathrm{NMR}$ spectroscopy. The dielectric behavior of the copolymer of VCN with vinyl acetate has been studied by Furukawa et al. ${ }^{20}$ The most important highlight in this investigation is the high dielectric strength above its $T_{\mathrm{g}}$ in non crystalline polymer. A mesophase glass structure has 
been proposed for this copolymer allowing cooperative effects in relation to dipolar motions of $\mathrm{CN}$ groups around the glass transition temperature. ${ }^{20}$ Industrial patents give the main characteristic of piezoelectric copolymers of $\mathrm{VCN} .^{21-23}$

For optical properties, industrial patents have claimed the synthesis of copolymers of VCN with functionalized styrenes such as 4 -acetoxystyrene ${ }^{24}$ or 4 -chloromethylstyrene ${ }^{25}$ or vinylcarboxyethyl benzoate ${ }^{26}$ to graft on these copolymers nonlinear species such as dies.

In the same way, many fluorinated (co)polymers have been studied for their outstanding properties (thermal stability, chemical inertness, resistance to oxidation and aggressive media, low refractive index, low surface tension, good electric properties and wire insulation). ${ }^{27-29}$ However, to our knowledge, a few studies on the synthesis of copolymers of VCN with fluorinated monomer has been reported in the literature, just like that of statistical copolymers of VCN with either 1,1-difluoro-2-2-dichloroethylene ${ }^{30}$ or 1,2-difluoro-1-2dichloroethylene. ${ }^{31}$ Montheard et al. ${ }^{32}$ have studied the radical copolymerization of VCN with two styrenic comonomers bearing a fluorinated chain in the para position, leading to alternating copolymers.

It is known that vinyl ethers do not homopolymerize under radical initiation. However, their copolymerization with electron-withdrawing monomers leads to alternating copolymer, via an accepter-donor copolymerization sometimes via a charge transfer complex. ${ }^{33}$ Two industrial examples are Lumiflon ${ }^{\circledR}$ and Zeffle ${ }^{\circledR}$ marketed by Asahi Glass Chemicals and Daikin Companies, from copolymers based on vinyl ethers with either chlorotrifluoroethylene or tetrafluoroethylene, respectively. ${ }^{33}$ The cationic polymerizations of fluorinated vinyl ethers such as 3,3,4,4-tetrafluorobutyl vinyl ether ${ }^{34}$ or $1 \mathrm{H}, 1 \mathrm{H}, 2 \mathrm{H}, 2 \mathrm{H}$-perfluorooctyl vinyl ether ${ }^{35}$ were pioneered by Choi et al. ${ }^{34}$ or by Vandooren et al. ${ }^{35}$, respectively. These reactions were initiated by the $\mathrm{HI} / \mathrm{ZI}_{2}$ system, leading to living poly(ethers) bearing fluoroalkyl side groups. Various groups also successfully attempted to carry out such procedures in various solvents ${ }^{36-}$ 38 and even in supercritical $\mathrm{CO}_{2}$ medium ${ }^{39}$. However, the dielectric properties of the resulting 
polymers have never been studied. Nevertheless, the cured films obtained by photocationic polymerization of a commercially available vinyl ether system in the presence of low amounts of $\omega$-perfluoro vinyl ether led to materials endowed with low wettability and friction which show peculiar characteristics for coating applications. ${ }^{40}$ The fluoromonomers increased the hydrophobicity of the film surface, whereas the adhesion on various substrates such as glass and wood was unchanged. An improvement in the chemical resistance of these coating was also observed: notwithstanding the very low concentration of the fluorinated monomers, the additives could protect the coating from aggressive solvents and may find suitable applications.

The objective of this article deals with the synthesis and the characterization of copolymers based on vinylidene cyanide (VCN) and a vinyl ether containing a fluorinated group. We have chosen $1 \mathrm{H}, 1 \mathrm{H}, 2 \mathrm{H}, 2 \mathrm{H}$-perfluorodecyl vinyl ether (FAVE8) as the fluorinated comonomer which has a flexible lateral chain making easier the orientation of cyanide dipole when the copolymer was poled. In addition, the presence of perfluoroalkyl group in FAVE8 could enhance the dipole moment of the polymeric chains and could provide new materials with interesting electric and surface properties. A kinetic approach enabled us to assess the reactivity ratios of both co-monomers and to compare them with those of the literature. Then, the thermal properties (especially the glass transition and decomposition temperatures) and the surface properties of the resulting copolymers have also been investigated.

\section{Experimental Part}

Materials: Vinylidene cyanide (VCN) was prepared by the pyrolysis of $1,1,3,3-$ tetracyanopropane at $180-250{ }^{\circ} \mathrm{C}$, as detailed elsewhere. ${ }^{41} 1,1,3,3$-Tetracyanopropane is prepared in the first step using the Knovenagel reaction, from formaldehyde and malonitrile as a compound possessing mobile hydrogen, in the presence of $\beta$-alanin as a base. Its melting 
point is about $136{ }^{\circ} \mathrm{C}$. The corresponding yield (ca. $80 \%$ ) was higher than that obtained when piperidine was used as the base to prepare the 1,1,3,3-tetracyanopropane as claimed by Bomogolova et al. ${ }^{42} \mathrm{VCN}$ is moisture sensitive, and polymerizes readily upon contact with water at room temperature to form a hard, white, and non-meltable polymer. ${ }^{6}$ Many efforts to stabilize vinylidene cyanide have been developed. The control of the time of this reaction is very important because the 1,1,3,3-tetracyanopropane intermediately can react with the base (even with moisture) to obtain the corresponding carbanion which can further react with the non-reacted formaldehyde leading to secondary compounds that have high melting points. ${ }^{4,16}$ At the end of the distillation, $\mathrm{VCN}$ monomer was kept at $-18{ }^{\circ} \mathrm{C}$ in the presence of a small amount of phosphorus pentoxide, and under nitrogen. The yield was $50 \%$.

Tert-Butylperoxypivalate (TBPPI, purity 75\%) was a gift from Akzo Nobel (Chalons sur Marne, France). 1H,1H,2H,2H-perfluorodecyl vinyl ether (FAVE8) was kindly supplied by Unimatec Company (Japan). Its purification was carried out by distillation under reduced pressure, then stored below $5{ }^{\circ} \mathrm{C}$ prior to use. Acetonitrile, $\mathrm{BF}_{3} . \mathrm{OEt}_{2}$, and 1,1,2-trichloro1,2,2-trifluoroethane $\left(\mathrm{CF}_{2} \mathrm{Cl}-\mathrm{CFCl}_{2}\right)$ were provided by Aldrich (38299 Saint QuentinFallavier, France).

\section{(Co)polymerizations}

\section{Cationic homopolymerization of FAVE8}

The homopolymerization of FAVE8 was initiated by $\mathrm{BF}_{3} . \mathrm{OEt}$, in 1,1,2-trichloro-1,2,2trifluoroethane as the solvent, under an anhydrous nitrogen atmosphere. First, a solution of 0.1 $\mathrm{M}$ of dried FAVE8 in 1,1,2-trichloro-1,2,2-trifluoroethane (dried using $\mathrm{CaH}_{2}$ and freshly distilled) was prepared and cooled to $-30{ }^{\circ} \mathrm{C}$ (in an acetone/liquid nitrogen bath) before the addition of $\mathrm{BF}_{3} . \mathrm{OEt}_{2}$ and then stirred for $3 \mathrm{hrs}$. Then, the reaction was deactivated by adding a large volume of methanol containing $5 \%$ in volume of ammoniac $(25 \%)$. The organic solution was washed by deionized water until a neutral $\mathrm{pH}$ was reached. Then it was dried 
over sodium sulfate $\left(\mathrm{Na}_{2} \mathrm{SO}_{4}\right)$ and filtered. Solvent was removed under vacuum. The resulting polymer was insoluble in usual organic solvents, expect in fluorinated solvent such as 1,1,2trichloro-1,2,2-trifluoroethane or 1,1,1,3,3-pentafluorobutane.

\section{Radical copolymerization of VCN with FAVE8}

The appropriate quantities of FAVE8 and initiator in dried acetonitrile (monomer/solvent=1/4 $\mathrm{w} / \mathrm{v}$ ) were placed in a two necked round bottom-flask and the mixture was purged with dry nitrogen. The flask was put a thermostatic oil bath at $75 \pm 1^{\circ} \mathrm{C}$. Then, freshly distilled VCN was added to that mixture. The copolymerization was allowed to proceed for about $10-20$ min. to achieve a conversion of about $12 \%$. The polymerization mixture was then poured into a tenfold excess of stirred pentane and the precipitated polymers were filtered, washed with the same non-solvent and dried under vacuum at $95^{\circ} \mathrm{C}$ for $24 \mathrm{hrs}$, to give a yellow powder.

Characterizations: The ${ }^{1} \mathrm{H}$ and ${ }^{19} \mathrm{~F}$ NMR spectra were recorded at ambient temperature on Bruker AC 200 and AC 400 instruments, using deuterated acetone or DMF as the solvents and tetramethylsilane (when the copolymers were soluble). TMS (or $\mathrm{CFCl}_{3}$ ) as the references for ${ }^{1} \mathrm{H}$ (or ${ }^{19} \mathrm{~F}$ ) nuclei, respectively. Coupling constants and chemical shifts are given in $\mathrm{Hz}$ and ppm, respectively. The experimental conditions for ${ }^{1} \mathrm{H}$ ( or ${ }^{19} \mathrm{~F}$ ) NMR spectra were the following: flip angle $90^{\circ}$ (or $30^{\circ}$ ), acquisition time $4.5 \mathrm{~s}$ (or $0.7 \mathrm{~s}$ ), pulse delay $2 \mathrm{~s}$ (or $5 \mathrm{~s}$ ), number of scans 16 (or 64) and a pulse width of $5 \mu$ s for ${ }^{19} \mathrm{~F}$ NMR.

Infrared spectroscopy measurements were performed in transmission with a spectrometer Nicolet 510 P. The accuracy was $\pm 2 \mathrm{~cm}^{-1}$.

Differential scanning calorimetry (DSC) measurements were conduced using a TA 2920 analyzer from TA instruments DA 73085, a RCS DA cooler and Sartorius MC5 weighing machine. Scans were recorded at a heating rate of $10^{\circ} \mathrm{C} \min ^{-1}$ from -50 to $180{ }^{\circ} \mathrm{C}$. 
Thermogravimetric analyses were performed with a Texas Instrument ATG 51-133 apparatus at the heating rate of $10{ }^{\circ} \mathrm{C} \cdot \mathrm{min}^{-1}$ from room temperature to $600{ }^{\circ} \mathrm{C}$ under nitrogen. The weight of copolymers ranging between 10 and $15 \mathrm{mg}$ was placed in a platinum pan.

The poly(VCN-alt-FAVE8) copolymers (as yellow gums) were sandwiched in two Teflon ${ }^{\circledR}$ films which were put between two heated plates of a press at $170{ }^{\circ} \mathrm{C}$ under 70 bar for $10 \mathrm{~min}$. The dynamic contact angle measurements were performed with a contact angle goniometer (contact angle system OCA Neurtek Instruments), equipped with a video camera and image analyzer, at room temperature with the sessile drop technique (each droplet's volume was ca. $6 \mu 1)$. At least five measurements were done; the difference from the average value was no more than $3^{\circ}$ for the advancing angle.

Scanning electron microscopy (SEM) was carried out on a FEI apparatus (resolution: 1.5-500 $\mathrm{nm}$ ), to obtain high level magnification images of cross sections of networks. A probe (using a gad cone) was used to observe surfaces within a $1 \mu \mathrm{m}^{3}$ scale at a working distance of 10 $\mathrm{mm}$.

Atomic force microscopy (AFM) was performed using a multimode scanning probe microscope (Park scientific Autoprobe CP) in intermittent-contact mode with a silicone tip. The AFM images were obtained at room temperature under air. The samples were prepared from spin-coating of the copolymer solution (in $\mathrm{C}_{4} \mathrm{~F}_{5} \mathrm{H}_{5}$ as the solvent) on glass substrates.

\section{Results and Discussion}

\section{Synthesis of Monomers}

Vinylidene cyanide monomer (VCN) is difficult to prepare and is highly reactive. ${ }^{4}$ It is moisture sensitive, and polymerizes readily upon contact with water at room temperature. Its synthesis was described by Bell et al. ${ }^{41}$ from the pyrolysis of 1,1,3,3-tetracyanopropane. The yield of VCN was close to $50 \%$. Many compounds have been tested as possible stabilizers 
for $\mathrm{VCN}$, and phosphorus pentoxide $\left(\mathrm{P}_{2} \mathrm{O}_{5}\right)$ and sulfur trioxide have been shown to behave as efficient stabilizers. ${ }^{43,44}$

$1 \mathrm{H}, 1 \mathrm{H}, 2 \mathrm{H}, 2 \mathrm{H}$-perfluorodecyl vinyl ether (FAVE8), used as comonomer of VCN, is a commercially available monomer. FAVE8 monomer was prepared by several authors $35,37,38,45$ from the transetherification of ethyl vinyl ether and $1 \mathrm{H}, 1 \mathrm{H}, 2 \mathrm{H}, 2 \mathrm{H}$-perfluorodecane-1-ol (Scheme 1).

\section{INSERT SCHEME 1}

\section{Cationic polymerization of $1 \mathrm{H}, 1 \mathrm{H}, 2 \mathrm{H}, 2 \mathrm{H}$-perfluorodecyl vinyl ether}

1H,1H,2H,2H-Perfluorodecyl vinyl ether (FAVE8) does not homopolymerize under radical initiation. ${ }^{35-38}$ but its cationic homopolymerization initiated by $\mathrm{BF}_{3}$.OEt was attempted (Scheme 2).

It is known that the polymers based on perfluorinated-containing vinyl ether are poorly soluble common usual organic solvents. ${ }^{34,35}$ Thus, our strategy was to carry out the cationic homopolymerization of FAVE8 in 1,2,2-trichloro-1,1,2-trifluoroethane as the solvent. Poly(FAVE8) homopolymer was also soluble in that chlorofluorinated solvent, but less soluble in organic solvents (such as THF, DMF, and dimethyl acetamide), which prevents from the measurement of their molecular weights by gel permeation chromatography (GPC or SEC).

\section{INSERT SCHEME 2}

3. Radical copolymerization of vinylidene cyanide with $1 \mathrm{H}, 1 \mathrm{H}, 2 \mathrm{H}, 2 \mathrm{H}$-perfluorodecyl vinyl ether

The radical copolymerization of VCN with non-fluorinated vinyl ether in benzene have been reported. ${ }^{4}$ Indeed, the vinyl ethers can be polymerized by cationic initiation ${ }^{46}$ in contrast to 
vinylidene cyanide for which the homopolymerization occurs by anionic initiation. ${ }^{3}$ The literature $^{4}$ reports that, the vinyl ether behaves as a base toward VCN, whereas VCN acts as an acid toward the ether monomer. Hall and Padias ${ }^{47}$ have reported that mixing VCN with alkyl vinyl ether (VE) at room temperature results in the homopolymerization of both the VE and VCN, cationic and anionic, respectively. This simultaneous cationic and anionic homopolymerization can be explained by the microdomains arising from the extreme polarity differences between both comonomers. Two polymers were isolated from these mixtures: a benzene-soluble polymer containing a high content of vinyl ether, and a benzene-insoluble polymer with a high VCN content. Moreover, Hall and Padias ${ }^{47}$ and Stille and Chung ${ }^{48}$ were able to isolate the cyclobutane adduct of the two olefins from the reaction mixture. The overall reaction is shown in Scheme 3.

\section{INSERT SCHEME 3}

This article also deals with the radical copolymerization of vinylidene cyanide (VCN) with 1H,1H,2H,2H-perfluorodecyl vinyl ether (FAVE8), initiated by tertio-butyl peroxypivalate (TBPPi) (the initial molar $[\mathrm{TBPP}]_{0} /\left([\mathrm{VCN}]_{0}+[\mathrm{FAVE} 8]_{0}\right)$ ratio was $\left.1.5 \mathrm{~mol} \%\right)$. That reaction was carried out in acetonitrile as the solvent (Scheme 2), and this solvent is well-known to be a good solvent which has a low transfer constant. ${ }^{49,50}$

Surprisingly, the radical copolymerization of VCN and FAVE8 occurred and led to an alternating copolymer as it was confirmed by elemental analysis and spectroscopy (as reported below). In a certain extent, the presence of the perfluorooctyl side group reduces the electron donating effect of FAVE8 comparatively to the non-fluorinated VE. However, the highly fluorinated and thus hydrophobic $\mathrm{C}_{8} \mathrm{~F}_{17}$ group interestingly enables to prevent from possible anionic homopolymerization of $\mathrm{VCN}$ in the presence of moisture. This induces that the radical copolymerization successfully took place in contrast to the ionic homopolymerizations of FAVE8 or of VCN. On the other hand, the perfluorinated group of 
the vinyl ether contributes to the formation of the charge-transfer complex ${ }^{29}$ between VCN and FAVE8 leading to an alternating structure.

The ${ }^{1} \mathrm{H}$ NMR spectrum of poly(VCN-co-FAVE8) copolymer shows the absence of ethylenic protons of both comonomers (centered at 6.5, 4.2, and $4.1 \mathrm{ppm}$ assigned to FAVE8 and the singlet centered at $6.8 \mathrm{ppm}$ for $\mathrm{VCN}$ ), the presence of a signal located at $2.0 \mathrm{ppm}$ corresponding to $\mathrm{CH}_{2}-\mathrm{C}_{8} \mathrm{~F}_{17}$ group, and the resonances at 4.0 and 1.2-1.6 ppm attributed to $\mathrm{CH}_{2}-\mathrm{O}$ and to methylenic protons of the main chain, respectively. The assignments were deduced by comparing those of the poly(FAVE8) homopolymer ${ }^{35}$ and those of the copolymers of VCN. ${ }^{32}$ The ${ }^{1} \mathrm{H}$ NMR spectrum also exhibits a signal centered at $0.9 \mathrm{ppm}$ which corresponds to the methyl group arising from the tert-butoxy radical generated by tbutyl peroxypivalate initiator. When heated, that initiator undergoes a homolytic scission leading to two following radicals: ${ }^{50,51}$

$\mathrm{t}-\mathrm{BuO}-\mathrm{OCOt}-\mathrm{Bu} \longrightarrow \mathrm{tBuO}^{\circ}+{ }^{\circ} \mathrm{OCOtBu}$

All the ${ }^{19} \mathrm{~F}$ NMR spectra of the synthesized poly(VCN-co-FAVE8) copolymers show the characteristic signals assigned to the $\mathrm{C}_{8} \mathrm{~F}_{17}$ group and indicates the incorporation of fluorinated monomer into the polymer by the presence of the $\mathrm{CF}_{3}$ group centered at $-82 \mathrm{ppm}$, the $\mathrm{CF}_{2}$ groups in the $-\left(\mathrm{CF}_{2}\right)_{6}-\mathrm{CF}_{3}$ chain ranging between -122 and $-128 \mathrm{ppm}$, and of the multiplet centered at -113 ppm characteristic of the $\mathrm{CF}_{2}$ group adjacent with the methylene group of the vinyl ether.

Figure 1 displays the IR spectra of FAVE8 monomer, poly(FAVE8) homopolymer and poly(VCN-alt-FAVE8) copolymer. It was noted that the frequencies of the vinyl bond $(\mathrm{C}=\mathrm{C})$ of FAVE8 (Figure 1a) and of VCN at $1620 \mathrm{~cm}^{-1}$ and $1626 \mathrm{~cm}^{-1}$, respectively, are absent, indicating the success of the copolymerization. The IR spectra of the poly(FAVE8) homopolymer and of the copolymer show strong frequencies attributed to C-F at about 1100$1250 \mathrm{~cm}^{-1}$, and the stretching bond at $2990 \mathrm{~cm}^{-1}$ assigned to aliphatic $\mathrm{C}-\mathrm{H}$ bonds. As for the 
poly(VCN-co-FAVE8) copolymer, the intensity of the $\mathrm{CN}$ frequency at $2270 \mathrm{~cm}^{-1}$ is weak and sometimes it is not observed as it was noted in several common copolymers based on $\mathrm{VCN}^{22,23}$ This does not mean that VCN has not been incorporated in the copolymer. Indeed, Bellamy ${ }^{52}$ studied the resonance of the $\mathrm{CN}$ group in unsaturated and saturated compounds. This author noted that the presence of strong $\mathrm{CN}$ dipoles in the backbone of the main chain due to VCN units increases the interaction between the chains.

\section{INSERT FIGURE 1}

\section{Kinetics of radical copolymerization of VCN with FAVE8}

The kinetics of radical copolymerization of VCN with FAVE8 was investigated from seven experiments achieved for $15 \mathrm{~min}$ at $75{ }^{\circ} \mathrm{C}$ from initial $[\mathrm{VCN}]_{0} /[\mathrm{FAVE} 8]_{0}$ molar ratios ranging between 15/85 and 80/20. After purification and precipitation, the copolymers were characterized by elemental analysis which enabled us to assess the mol. \% of both comonomers in the copolymers. By making use of the percentages of nitrogen and fluorine atoms in the copolymers, two equations have been derived to find out the mol. \% of the comonomers:

$$
\% N=\frac{28 \times \alpha}{\alpha \times M_{V C N}+\beta \times M_{F A V E 8}} \times 100 \quad \% F=\frac{323 \times \beta}{\alpha \times M_{V C N}+\beta \times M_{F A V E 8}} \times 100
$$

where $\alpha$ and $\beta$ stand for the molar percentages of VCN and of FAVE8 in the copolymer, respectively $(\alpha+\beta=100 \%)$, while $\mathrm{M}_{\mathrm{VCN}}$ and $\mathrm{M}_{\mathrm{FAVE} 8}$ represent the molecular weights of VCN (78.02 g.mol ${ }^{-1}$ ) and of FAVE8 (490.02 g.mol $\left.{ }^{-1}\right)$. The values of the percentages of both comonomers incorporated in the copolymers were calculated from arithmetic mean of nitrogen and fluorine percentages. Table 1 summarizes the results and shows that except for the first experiment, all the produced poly(VDF-co-FAVE) copolymers have the same equimolar composition of both comonomers. 


\section{INSERT TABLE 1}

Various laws to assess the reactivity ratios have been suggested by different authors. We have used three different laws: from Fineman and Ross' method ${ }^{53}$, from Kelen and Tüdos's law ${ }^{54}$, and the Revised Patterns Scheme. ${ }^{55-59}$

First, the reactivity ratios, $r_{12}$ of $\operatorname{VCN}$ (1) and $r_{21}$ of FAVE8 (2) were assessed from the Fineman-Ross (FR) equation ${ }^{53}$ from the composition of monomers, in the mixture and in the copolymer at low conversion, and is detailed in the Supporting Information. Table 2 summarizes the different parameters to determine the reactivity ratios for the copolymerization of VCN with FAVE8 from the Fineman-Ross ${ }^{53}$ (and the Kelen-Tüdos ${ }^{54}$ ) laws. Hence, plotting $G$ versus $H$ gave a straight line (Figure 3 in the Supporting Information), the slope of which led to $r_{12}=0.07$ while the intercept gave $r_{21}=0.06$ at $75{ }^{\circ} \mathrm{C}$.

The second method to determine the reactivity ratios was derived by Kelen and Tüdos ${ }^{54}$ (also detailed in the supporting information), leading to $\mathrm{r}_{12}=0.09$ and $\mathrm{r}_{21}=0.08$ at $75^{\circ} \mathrm{C}$.

However, the interpretation of the reactivity of polymer radicals has been developed by means of some improvements in more recent methods of assessment of reactivity ratios suggested by Jenkins ${ }^{55-59}$ or by O'Discroll and Reilly. ${ }^{60}$ These methods are regarded as advances over the Alfrey-Price Q-e principle. ${ }^{61}$ It is assumed that the rate of reaction of a given radical with a given substrate is governed partly by a "general"-i.e. thermodynamicfactor (reflecting the extent of the electron delocalization) and polar factor. Indeed, Jenkins ${ }^{56-}$ 59 extensively reviewed and reshuffled the concept and suggested the « Revised Patterns Schemes » that corresponds to the insertion of Basic Monomer Set as a new polarity parameter) and that forecasting monomer reactivity ratios was hence possible with much greater precision than heretofore. Indeed, the condensed version of the Revised Patterns Scheme (i.e. Patterns A, S Scheme, reported by Jenkins ${ }^{57-59}$ ) was used, involving styrene (S) and acrylonitrile (A) as non polar and highly polar monomers, respectively. That method 
enables the assessment of $r_{12}$ and $r_{21}$ and takes into account various reactivity ratios, as follows:

$$
\begin{aligned}
& \log \left(r_{12}\right)=\log \left[\left(r_{1 S}\right)\left(r_{S 2}\right)\right]-\frac{\left(\log \left[\left(r_{A S}\right)\left(r_{S 2}\right) /\left(r_{A 2}\right)\right]\right)\left(\log \left[\left(r_{S A}\right)\left(r_{1 S}\right) /\left(r_{1 A}\right)\right]\right.}{\log \left[\left(r_{A S}\right)\left(r_{S A}\right)\right]} \\
& \log \left(r_{21}\right)=\log \left[\left(r_{2 S}\right)\left(r_{S 1}\right)\right]-\frac{\left(\log \left[\left(r_{A S}\right)\left(r_{S 1}\right) /\left(r_{A 1}\right)\right]\right)\left(\log \left[\left(r_{S A}\right)\left(r_{2 S}\right) /\left(r_{2 A}\right)\right]\right)}{\log \left[\left(r_{A S}\right)\left(r_{S A}\right)\right]}
\end{aligned}
$$

where $r_{12}, r_{21}, r_{1 S}, r_{S 2}, r_{A S}, r_{A 2}, r_{S A}, r_{1 A}, r_{2 S}, r_{S 1}, r_{A 1}$, and $r_{2 A}$ stand for the reactivity ratio of VCN monomer (1) in the radical copolymerization of VCN (1) and FAVE8 (2), the reactivity ratio of monomer FAVE8 (2) in the copolymerization of VCN (1) and FAVE8 (2), the reactivity ratio of monomer VCN (1) in the copolymerization of VCN (1) and styrene (S), the reactivity ratio of styrene (S) in the copolymerization of styrene (S) and FAVE8 (2), the reactivity ratio of acrylonitrile (AN) in the copolymerization of $\mathrm{AN}$ and styrene, the reactivity ratio of styrene in the copolymerization of AN with FAVE8 (2), the reactivity ratio of $\mathrm{S}$ in the copolymerization of S with $\mathrm{AN}$, the reactivity ratio of $\mathrm{VCN}$ (1) in the copolymerization of VCN (1) with AN, the reactivity ratio of FAVE8 (2) in the copolymerization of FAVE8 (2) with $\mathrm{S}$, the reactivity ratio of styrene in the copolymerization of S with VCN (1), the reactivity ratio of $\mathrm{AN}$ in the copolymerization of $\mathrm{AN}$ with $\mathrm{VCN}$ (1), the reactivity ratio of FAVE8 (2) in the copolymerization du FAVE8 (2) with AN. According to the literature, the following reactivity ratios of styrene, acrylonitrile, VCN, and FAVE8 have been determined: $\mathrm{r}_{\mathrm{AS}}=0.04^{56}, \mathrm{r}_{\mathrm{SA}}=0.38^{56}, \mathrm{r}_{1 \mathrm{~S}}=0.001^{5}, \mathrm{r}_{\mathrm{S} 1}=0.003^{5}, \mathrm{r}_{2 \mathrm{~S}}=1.20^{62}, \mathrm{r}_{\mathrm{S} 2}=152^{62}, \mathrm{r}_{\mathrm{A} 2}=0.94^{63}$ and $\mathrm{r}_{2 \mathrm{~A}}=0.02^{63}$ (or 0.06 considering a vinyl ether from the Greenley database ${ }^{64}$ ).

The $r_{1 \mathrm{~A}}$ and $\mathrm{r}_{\mathrm{A} 1}$ values were calculated from the examples disclosed in a Goodrich patent ${ }^{65}$ : $\mathrm{r}_{1 \mathrm{~A}}=3.34$ and $\mathrm{r}_{\mathrm{A} 1}=1.24$.

This calculation led to $\mathrm{r}_{12}=2.7 \times 10^{-3}$ and $\mathrm{r}_{21}=4.0 \times 10^{-6}$ at $75^{\circ} \mathrm{C}\left(\mathrm{r}_{12} \mathrm{x} \mathrm{r}_{21}=1.1 \times 10^{-8}=0\right)$. Hence, from the Revised Patterns Scheme ${ }^{56-59}$ a better accuracy was noted and shows, as expected, that FAVE does not homopolymerize under radical conditions.

Indeed, all these laws agree on the alternated structure of the poly(VCN-alt-FAVE8) copolymers. 


\section{INSERT TABLE 2}

Figure 2 represents the monomer-polymer composition diagramme of mol. \% VCN in the copolymer versus mol.\% VCN in feed. For each composition in feed $\left(f_{\mathrm{VCN}}\right)$, the value of the respective composition in the copolymer $\left(\mathrm{F}_{\mathrm{VCN}}\right)$ shows a copolymer composition close to $50 \%$ of VCN from 15 to $80 \mathrm{~mol} \%$ in feed, (except for $\mathrm{f}_{\mathrm{VCN}}=0.15, \mathrm{~F}_{\mathrm{VCN}}=0.32$ data for which the composition is rich in FAVE8), confirming that the copolymer has an alternating structure.

\section{INSERT FIGURE 2}

Because $r_{12}<1$ and $r_{21}<<1$, one can consider that the rate constants $k$ can be compared as follows: $k_{11}<k_{12} ; k_{22}<<k_{21}$ showing that the radical $\sim \sim \mathrm{CH}_{2}-\mathrm{C}^{\bullet}(\mathrm{CN})_{2}$ has a high tendency to react with FAVE8. In addition, the synthesized alternating copolymer could be the result of the electron donor/electron acceptor behavior of the couple.

These values can be compared to those of other comonomers able to copolymerize with VCN. Table 3 lists the monomer reactivity ratios $\left(r_{12}\right.$ and $\left.r_{21}\right), r_{12} \times r_{21}$ products, and the relative reactivities $\left(1 / \mathrm{r}_{12}\right)$ of vinylidene cyanide with several comonomers. All of the values were not determined in the same conditions of temperature, but no effect of temperature upon reactivity ratios was found in the studied range $\left(0-50{ }^{\circ} \mathrm{C}\right) .^{5}$

Interestingly, $\mathrm{VCN}$ is a monomer able to copolymerize with several comonomers in alternating way. These monomers can be methacrylates, styrenes, vinyl esters (including vinyl acetate and vinyl benzoate) and vinyl chloride.

Table 3 allows us to compare the reactivity ratios of various co-monomers ( $\alpha$ acetoxyacrylates, ${ }^{66,67}$ acrylate, styrenic, vinylic and diene monomers) to those of other pairs involving VCN. The most active comonomers (styrene, 2-chloro-1,3-butadiene, 2,5dichlorostyrene, methyl methacrylate) have electron-rich double bonds. ${ }^{68}$ The less active 
comonomers (acrylic acid, vinyl chloride and maleic anhydride) bear electron-poor double bonds.

The strong tendency of $\mathrm{VCN}$ to alternate in the course of the copolymerization is immediately apparent from the data listed in Table 3 . Six of the copolymers have $r_{12} \times r_{21}$ products lower than $9.0 \times 10^{-4}$ and that obtained from the reactivity ratios assessed from the Revised Patterns Scheme is $1.1 \times 10^{-8}$.

\section{INSERT TABLE 3}

It was worth to supply a reactivity series of monomers about VCN. The traditional method for the determination of the relative reactivity of a macroradical to several monomers was used. Indeed, it is common to compare the values of $1 / \mathrm{r}_{12}=\mathrm{k}_{12} / \mathrm{k}_{11}$ as the ratio of rate constants of cross propagation $\left(\mathrm{k}_{12}\right)$ to that of homopropagation $\left(\mathrm{k}_{11}\right)$. Therefore, the higher the $1 / \mathrm{r}$ value, the more able the radical to react with the second monomer. Table 3 allows us to suggest the following series of relative reactivities of monomers to $\sim \sim \mathrm{VCN}^{\bullet}$ radicals:

Maleic anhydride $<$ cis-dichloroethylene $\approx$ trans-dichloroethylene $<$ Vinyl choride $<$ Acrylic acid $<2$-chloroprene $\approx$ Ethyl $\alpha$-acetoxyacrylate $<$ Vinyl chloroacetate $<\alpha$-acetoxystyrene $<$ Vinyl acetate $<$ Methyl $\alpha$-acetoxyacrylate $\approx$ Vinyl benzoate $<$ Methyl $\alpha$-chloroacrylate $<$ Vinylidene chloride $<$ Methyl methacrylate $<2,5$-dichlorostyrene $<2$-chloro-1,3-butadiene $<$ FAVE (from the Revised Patterns Scheme) <Styrene, although additional kinetics are necessary since the experimental conditions, the chosen method to assess the reactivity ratios, and the nature of the radical initiators are different. Hence, it is shown that FAVE8 monomer leads to highly alternating structure and is also more reactive towards $\backsim \sim \mathrm{VCN}^{\bullet}$ radicals. 


\section{Thermal properties of poly(VCN-alt-FAVE8) copolymers}

DSC analysis was carried out by increasing the temperature of $2^{\circ} \mathrm{C} / \mathrm{min}$, while carrying out two scans. The DSC thermogram goes up that this alternating fluoronitrile polymer has $\mathrm{Tg}$ values of approximately $107{ }^{\circ} \mathrm{C}$ and a melting point $\left(\mathrm{T}_{\mathrm{m}}\right)$ at about $170{ }^{\circ} \mathrm{C}$ attributed to the perfluorooctyl groups. This $\mathrm{T}_{\mathrm{m}}$ is higher in comparison to that of poly(FAVE8) homopolymer which possess a melting point at $42{ }^{\circ} \mathrm{C}$ and confirmed the incorporation of VCN units. To conclude, it can be claimed that the poly(VCN-alt-FAVE8) copolymer exhibits better thermal properties than those of the respective homopolymer.

Furthermore, the thermogravimetric analysis of the poly(VCN-alt-FAVE8) copolymer shows a high thermal stability. Figure 3 shows the temperature when the copolymer starts to decompose $\left(300{ }^{\circ} \mathrm{C}, 2 \%\right.$ of weight loss $)$ and the degradation temperature of this copolymer $\left(350{ }^{\circ} \mathrm{C}\right)$ corresponding to $7 \%$ weight loss. It is noted that the poly(VCN) homopolymer has a low temperature of degradation at about $160{ }^{\circ} \mathrm{C}$ with depolymerization of degradation mechanism as it was suggested by Grassie and Mc Gucham. ${ }^{69}$ This result confirms the absence of VCN-VCN diad in the copolymer and thus supplies a further evidence of its alternating structure. To complete this study, it was worth investigating the temperature of degradation of poly(FAVE8) homopolymer. It was found a weight loss of $20 \%$ from $200{ }^{\circ} \mathrm{C}$ and a second weight loss at higher temperatures $\left(>400^{\circ} \mathrm{C}\right)$.

\section{INSERT FIGURE 3}

\section{Surface properties of poly(VCN-alt-FAVE8) copolymers}

The films were processed from poly(VCN-alt-FAVE8) copolymers by press at $170{ }^{\circ} \mathrm{C}$. The wettability of the films was studied by contact angle measurements with water (WCA), while oleophobic properties were achieved in a similar manner with diiodomethane as the apolar solvent. As shown in Figure 4, the water contact angle is $168 \pm 3^{\circ}$, indicating that superhydrophobic surfaces are obtained, showing that the $\mathrm{C}_{8} \mathrm{~F}_{17}$ groups migrated to the 
extreme surface of the film, and probably the $\mathrm{CN}$ groups also have a certain input. Indeed, measurements of the angle were sometimes not easy since the sphere of water moved and even escaped from the film as soon as it was deposited (indeed a drop of $2 \mu 1$ was not easy to be deposited and it was required to increase the volume of the drop (ca. $6 \mu \mathrm{l}$ ) until it fell down). This may arise from the $\mathrm{C}_{8} \mathrm{~F}_{17}$ perfluorinated side group enhanced by the softness brought by the $-\mathrm{OCH}_{2} \mathrm{CH}_{2}$ - spacer between the backbone and that fluorinated dangling group. Such a highly hydrophobic characteristic was not observed on poly $(1 \mathrm{H}, 1 \mathrm{H}, 2 \mathrm{H}, 2 \mathrm{H}-$ perfluorodecyl acrylate) $\left(\mathrm{WCA}=130^{\circ}\right)^{70}$ probably because the ester group is too stiff. Possible intramolecular complexes between the nitrile groups with adjacent FAVE8 unit may occur (IR spectra above may give an evidence) which also may induce physical crosslinking as we noted on a couple of non-soluble samples. The effect of side chain length on the surface properties of poly(fluororalkyl acrylate) thin films were studied by Honda et al. ${ }^{70}$ who revealed that a perfluorinated group containing more than 8 carbon atoms was crystalline and formed ordered structure. This result leads to a high water-repellent mechanism. Acatay et $a .^{71}$ reported the WCA assessments of a perfluorinated polymer under electric field. These authors also showed that the orientation of apolar fluorinated groups led to a high hydrophobicity (WCA, $167^{\circ}$ ). In our present case, it was not necessary to direct the dipole of VCN because these nitrile groups are located in both sides of the polymeric chain. Nyström et al. ${ }^{72}$ have studied the effect of the functionalization of a bio-fibre surface by different functions. The highest WCA was obtained using PGMA- $\mathrm{C}_{7} \mathrm{~F}_{15}\left(161^{\circ}\right)$.

In addition, to be chemically hydrophobic and to achieve a superhydrophobic state, a material must also exhibit a surface topography of at least bilevel roughness ${ }^{72}$. The scanning electron microscopy (SEM) analysis has shown that the surfaces of the films are rough (Figure 4c). Figure 5 shows the atomic force microscopy (AFM) 3D typological image of poly(VCN-altFAVE-8) copolymer. The surface roughness, defined as the root-mean-square of the height deviations taken from the mean data plane, was $1.72 \mathrm{~nm}$ over $25 \mu \mathrm{m} * 25 \mu \mathrm{m}$ scan. The AFM 
image shows a homogeneous surface with white nodules of ca. 3-8 nm, assigned to crystalline $\mathrm{C}_{8} \mathrm{~F}_{17}$ segments.

Tests of wettability with diiodomethane were also carried out. In this case too, the high value $\left(135^{\circ}\right)$ of the contact angle indicates that the surface was highly oleophobic. Oleophobicity is a very interesting property as it also means that the film behaves as a dirt repellent and antigraffiti. Indeed, deeper investigation on these interesting surface properties by AFM is under progress and additional investigations are required (isotropization temperature, crystalline structures, XPS of the extreme surface).

\section{INSERT FIGURE 4}

\section{INSERT FIGURE 5}

\section{Conclusion}

While $1 \mathrm{H}, 1 \mathrm{H}, 2 \mathrm{H}, 2 \mathrm{H}$-perfluorodecyl vinyl ether and $\mathrm{VCN}$ homopolymerize under cationic or anionic conditions, respectively, the challenge to copolymerize them under radical conditions was fulfilled. In addition, that copolymerization led to alternating copolymers with exceptional high thermal stability. It can be concluded that the radical copolymerization of VCN with a vinyl ether bearing a perfluorinated side group gave interesting copolymers, in contrast to the radical homopolymerization of FAVE8 which was not produced. ${ }^{1} \mathrm{H},{ }^{19} \mathrm{~F}$ and IR spectroscopy and elemental analysis were used to characterize the structures of these copolymers. The kinetics of copolymerization were investigated for each monomer from the series of at least seven reactions for which the initial $[\mathrm{VCN}]_{0} /[\mathrm{FAVE} 8]_{0}$ molar ratios ranged between $15 / 85$ and $80 / 20$. The curve fitting of the copolymeric composition versus initial monomer composition and Fineman-Ross and Kelen Tüdos laws were used to calculate the reactivity ratios $\left(\mathrm{r}_{12}=\mathrm{r}_{\mathrm{VCN}}=0.08 \pm 0.01 ; \mathrm{r}_{21}=\mathrm{r}_{\mathrm{FAVE} 8}=0.07 \pm 0.01 ; \mathrm{r}_{12} \mathrm{x} \mathrm{r}_{21}=6 \times 10^{-3}\right.$ at 75 
${ }^{\circ} \mathrm{C}$ ) while the Revised Patterns A,S Scheme indicated $\mathrm{r}_{12}=2.7 \times 10^{-3}$ and $\mathrm{r}_{21}=4.0 \times 10^{-6}$ suggested an alternating tendency in that radical copolymerization. TGA analysis revealed that the poly(VCN) homopolymer is poorly thermostable, but the incorporation of FAVE8 units in poly(VCN-alt-FAVE8) copolymer showed a very high thermal stability as the starting decomposition temperature is around $350{ }^{\circ} \mathrm{C}$. These poly(VCN-alt-FAVE8) copolymers were processed into films, the surface properties of which were assessed by contact angles. Superhydrophobic and highly oleophobic surfaces were noted as evidenced by the water and diiodomethane contact angles worthing $168 \pm 3^{\circ}$ and $135 \pm 3^{\circ}$, respectively. Further investigation concerning the electrical properties of these original alternating copolymers is also under progress.

\section{Acknowledgments}

The authors thank the CNRST (Morocco)-CNRS (France) programme (Convention \# 18541 Chimie 07/05), the PROTARS programme ( ${ }^{\circ}$ D13/16) and the "Agence Universitaire de la Francophonie" (AUF: 6301PS336, P6411/3089), for their financial supports. The authors would also like to thank the Unimatec Company- Japan (Drs Kokin and Sonoi) for the generous gift of 1H,1H,2H,2H-perfluorodecyl vinyl ether (FAVE8), and Dr Grill and Dr Ramonda for SEM and AFM measurements, respectively.

Supporting Information Available: ${ }^{19} \mathrm{~F}$ and ${ }^{1} \mathrm{H}$ NMR spectra of homopolymers and copolymers and the assessments of the reactivity ratios from Fineman and Ross and from Kelen and Tüdos methods. This material is available free of charge via the Internet at http://pubs.acs.org. 


\section{Reference and Notes}

(1) Gerhard-Multhaup, R. Ferroelectrics, 1987, 75, 385-393.

(2) Greszta, D.; Mardare, D.; Matyjaszewski, K. Macromolecules, 1994, 27, 638-641.

(3) Gilbert, H.; Miller, F.F.; Averill, S.J.; Schmidt, R.F.; Steward, F.S.; Trumbull, H. L. J. Am. Chem. Soc., 1954 ,76, 1074-1076.

(4) Conciatore, A. B.; Trapasso, L. E.; Stackman, R. W. Vinylidene cyanide polymers, Encyclopedia of Polymer Science and Technology. J. Wiley, 1st Edition; NewYork 1971, Vol. 14.

(5) Gilbert, H.; Miller, F.F.; Averill, S.J.; Carlson, E.L.; Flot, V.L.; Heller, H. J.; Steward, F.S.; Schmidt, R.F.; Trumbull, H. L. J. Am. Chem. Soc. 1956 , 78, 1669-1673.

(6) Sprague, S.; Greene, H.E.; Reuter, L.F.; Smith, R.D. Angew. Chem. Internat. Ed. 1962, 1, 425-428.

(7) Goodrich, B.F. U.S. Patent. 1956/756, 839.

(8) Miyata, S.; Yoshikawa, M.; Tasaka, S.; Ko, M. Polymer. J. 1980, 12, 875-882.

(9) Tasaka, S.; Miyasato, K.; Yoshikawa, M.; Miyata, S.; Ko, M. Ferroelectrics. 1984, 57, 267-278.

(10) Harrison, J.S.; Ounaies, Z. Piezoelectric Polymers, NASA/ Cr-2001-21142, ICASE. 2001, Report $N^{\circ}$ 2001-43.

(11) Inoue, Y.; Kashiwasaki, A.; Maruyama, Y.; Yo, Y.S.; Chujo, R.; Seo, I.; Kishimoto, M. Polymer. 1988, 29, 144-150.

(12) Maruyama, Y.; Yo, Y.S.; Inoue, Y.; Chujo, R.; Tasaka, S.; Miyata, S. Polymer. 1987, 28,1087-1094.

(13) Inoue, Y.; Kawaguchi, K.; Maruyama, Y; Yo, Y.S.; Chujo, R.; Seo, I.; Kishimoto, M. Polymer. 1989, 30, 698-706.

(14) Kishimoto, M.; Nakajima, K.; Seo, I. (Mitsubishi Petrochemical Co, Ltd), US Patent. 1991/4, 999,0584.

(15) Inoue, Y.; Ohta, Y.; Sakurai, M.; Chûjô, R.; Seo, I.; Kishimoto, M. Polymer. 1994, 35, 718-425.

(16) Montheard, J. P.; Boinon, B.; Belfkira, A.; Raihane, M.; Pham, Q. T. Makromol. Chem. 1993, 194, 2839-2847.

(17) Montheard, J. P.; Boinon, B.; Belfkira, A.; Sadel, A.; Pham, Q.T. Poly. Bull. 1992, 28, 615-623.

(18) Ohta, Y.; Inoue, Y.; Chûjô, R.; Kishimoto, M.; Seo, I. Polymer, 1990, 31,1581-1589. 
(19) Jo, Y.S.; Inoue, Y.; Chûjô, R.; Saito, K.; Miyata, S. Macromolecules, 1985, 18, 18501857.

(20) Furukawa, T. Date, M.; Nakajima, K.; Kosaka, T.; Seo, I. Jpn. J. App. Phys. 1986, $25,1178-1183$.

(21) Kihimito, M.; Nakajima, K.; Seo, I.Mitsubishi Petrochemical. EP. 1988/ 0,264,240, Chem. Abstr. 1988, 109, 171102.

(22) Kihimito, M.; Seo, I.; Fujimoto, Y. Mitsubishi Petrochemical. EP. 1991/ 0,415,342, Chem. Abstr. 1991, 115, 009621.

(23) East, A.; Conciatori, AB. Hoechst Celanese PCT. WO. 1991 / 013,922, Chem. Abstr. 1991, 116, 7371.

(24) East, A.; Conciatori, AB. Hoechst Celanese Corporation U.S. Pat. 1991 / 5,061,760, Chem. Abstr. 1992, 117, 49861.

(25) Mitsubishi Petrochemical. Jap Pat. 1991/03,207,612, Chem. Abst. 1992, 166, 265249.

(26) Kishimoto, M.; Seo, I.; Fujimoto, Y. Mitsubishi Petrochemical. Eur . Pat. 1992/ 0,477, 565, Kishimoto, M.; Seo, I.; Oda, A.; Oshadi, Y.; Zou, D. Chem. Abstr. 1992, 117, 192976.

(27) Scheirs, J. Modern Fluoropolymers, Wiley, New York, 1997

(28) Hougham, G.; Cassidy, P.; Davidson, T.; Johns, K. Fluoropolymers, Kluvert New York, 1999.

(29) Ameduri, B.; Boutevin, B. Well Architectured Fluoropolymers: Synthesis, Properties and Application, Elsevier, Amsterdam, 2004.

(30) Gilbert, H.; Miller, F.F.; Folt V.L. (B.F. Goodrich) U.S.Pat. 1953/2,650,911.

(31) Gilbert, H.; Miller, F.F. (B.F. Goodrich) U.S.Pat. 1953/ 2,654,728.

(32) Montheard, J.P.; Zerroukhi, A.; Ouillon, I.; Boinon, B.; Pham, Q.T., Macromol. Rep. 1995, A32 (Suppl. 1 and 2), 1-9.

(33) a) Asahi Glass Co, French Patent 1988/015,212; b) Takakura, T., CTFE/Vinyl ether copolymers, in ref [27], chapter 29, pp 557-564.

(34) Choi, W. O.; Sawamoto, M.; Higashimura, T. Polym. J. 1988, 20, 201-209.

(35) a) Vandooren, C.; Jérôme, R.; Teyssié, P. Polym. Bull. 1994, 32, 387-395.

b) Vandooren, C. PhD Dissertation, University of Liège (Belgium), 1994.

(36) Hopken, J.; Moeller, M.; Lee, M.; Percec, V. Makromol. Chem. 1992,193, 275-283.

(37) Percec, V.; Lee, M., J. Macromol. Sci. Pure Appl. Chem. 1992, A29, 723. 
(38) Castelvetro, V.; Pittaluga, G.B.; Ciardelli, F.; Macromol. Chem. Phys. 2001, 202, 20932103.

(39) Clark, M. R.; DeSimone, J.M.; Macromolecules. 1995, 28, 3002.

(40) Bongiovanni, R.; Sangermano, M; Malucelli, G.; Priola, A.; Leonardi, A.; Ameduri, B.; Pollicino, A.; Recca, A. J. Polym. Sci. Part A; Polym. Chem. 2003, 41, 2890.

(41) Bell, R.A.; Brown, B.; Duarte.; Howard-Lock, HC.; Lock, JL. Canadian J. Chem. 1987, 65 (2) 261.

(42) Bogomolova, L.I.; Gorker, I.A; Kochetkova, S.A. Methody. Poluch. Khim. Reakt. Prep. 1969, 18, 50-54, Chem. Abstr. 1972, 76, 14964y.

(43) Miller, F.F. (B.F. Goordich), U.S. Pat. 1952/ 2,614,118.

(44) Ardis, A. E. (B.F. Goordich), U.S. Pat. 1954 / 2,665,299.

(45) Boutevin, B.; Youssef, B. J. Fluorine Chem. 1989, 44, 395-402.

(46) Eley, D.D.; Richards, A. W. Trans. Faraday Soc. 1949, 45, 423-429.

(47) Hall, Jr, H.K.; Padias, A.B. Aldrichimica Acta. 1995, 28, 37-43.

(48) Stille, J.K.; Chung, T.C. Macromolecules. 1975, 8, 114-121.

(49) Russo, S.; Behari, K.; Chengji, S.; Pianca, M.; Barchiesi, E.; Moggi, G. Polymer. 1993, 34, 4777-4787.

(50) Guiot, J.; Ameduri, B.; Boutevin, B. Macromolecules. 2002, 35, 8694-8707.

(51) Kostov, G.; Tredwell, M.; Gouverneur, V.; Ameduri, B. J. Polym. Sci; Part A; Polym. Chem. 2007, 45, 3843-3850.

(52) Bellamy, L.J. The infrared Spectra of complex Molecules, Chapman et Hall, J. Wiley Inc, New York 1975, V.1, Third Ed.

(53) Fineman, M.; Ross, S.D. J. Polym. Sci. 1950, 5, 259-265.

(54) Kelen, T.; Tüdos, F. J., Macromol. Sci. Chem. 1975, A: 9,1-7.

(55) Jenkins, A.D.; Eur. Polym. J, 1989, 25, 721-723.

(56) Jenkins, A.D.; Jenkins, J.; Macromol. Symp. 1996, 111, 159-169.

(57) Jenkins, A.D.; J. Polym. Sci : Part A : Polym. Chem.1996, 34, 3495-3510.

(58) Jenkins, A.D.; J. Polym. Sci : Part A : Polym. Chem.1999, 37, 113-126.

(59) Jenkins, A.D.; Macromol. Symp. 2001, 111, 159-169. 
(60) O’Discroll, K.F.; Reilly, P.M., Makromol. Chem. Macromol. Symp. 1987, 10/11, 355374.

(61) Alfrey, T.; Price, C.C. J. Polym. Sci. 1974, 2, 101-106.

(62) Chang, E.Y.C.; Price, C.C.; J. Am. Chem. Soc. 1961 , 83, 4650-4654.

(63) Barton, I.M.; Butler, G.B.; Chapin, E.C.; J. Polym. Sci. 1965, A3, 501-505.

(64) a) Greenley, R.Z.; J. Macromol. Sci. Chem, A, 1980, 4, 427, 1980; b) Brandrup, J.; Immergut, E.H.; Grulke, E.A. Polymer Handbook, Wiley, NewYork 2003, 4th. Ed p II-319.

(65) Gilbert, H.; (B.F. Goordich), US Patent 1953/ 2,628,954.

(66) Montheard, J. P. ; Zerroukhi, A.; Ouillon, I ; Raihane, M.; Pham, Q.T. Polym. Bull. 1996, 36, 709-716.

(67) Tanaka, H.; Okazaki, T.; Tezuka. Y.; Hongo, T.; Takahashi, Y. Polymer. 2002, 43, 11891196.

(68) Price, C.C. Mechanisms of reactions at carbon-carbon double bonds, Intersience Publishers, Inc, New York, 1945, p. 96.

(69) Grassie, N.; McGuchan, R. Eur. Polym. 1972, 8, 245-251.

(70) Honda, K.; Morita, M.; Otsuki, H.; Takahara, A. Macromolecules. 2005, 38, 5699-5706.

(71) Acatay, K.; Simsek, E.; Ow-Yong, C.; Menceloglu, Y.Z. Angew. Chem. Int. Ed. 2004, 43, 5210-5219.

(72) Nyström, D. ; Lindqvist, J. ; Östmark, E. ; Antoni, P. ; Malkoch, M. ; Johansson, M. ; Malmström, E. ; Hult, A. Polymer preprints. 2007, 48 (2), 175-176. 


\section{SCHEME CAPTIONS}

Scheme 1. Synthesis of $1 \mathrm{H}, 1 \mathrm{H}, 2 \mathrm{H}, 2 \mathrm{H}-$ perfluorodecyl vinyl ether (FAVE8)

Scheme 2. (a) Radical copolymerization of Vinylidene cyanide (VCN) with $1 \mathrm{H}, 1 \mathrm{H}, 2 \mathrm{H}, 2 \mathrm{H}-$ perfluorodecyl vinyl ether (FAVE8) at $75{ }^{\circ} \mathrm{C}$ in acetonitrile, initiated with tertio-butyl peroxypivalate

(b) Cationic homopolymerization of FAVE8 initiated by $\mathrm{BF}_{3} . \mathrm{OEt}$ at $-30{ }^{\circ} \mathrm{C}$ in $1,1,2$-trichloro1,2,2-trifluoroethane

Scheme 3. Different ways of reaction between a vinyl ether (VE) and vinylidene cyanide $(\mathrm{VCN})$ 


\section{TABLE CAPTIONS}

Table 1. Monomer/copolymer compositions from the kinetics of radical copolymerization of vinylidene cyanide (VCN) with $1 \mathrm{H}, 1 \mathrm{H}, 2 \mathrm{H}, 2 \mathrm{H}$-perfluorodecyl vinyl ether (FAVE8) determined by elemental analysis. Copolymerization conditions: $[\mathrm{tBu}-\mathrm{OO}-\mathrm{CO}-\mathrm{tBu}]_{0} /\left([\mathrm{VCN}]_{0}\right.$ $\left.+[\text { FAVE8 }]_{0}\right)=1.5 \mathrm{~mol} . \%, 75^{\circ} \mathrm{C}$ for $15 \mathrm{~min}$.

Table 2. Fineman-Ross and Kelen-Tüdos parameters for the radical copolymerization of vinylidene cyanide (VCN) with 1H,1H,2H,2H-perfluorodecyl vinyl ether (FAVE8).

Table 3. Reactivity ratios of vinylidene cyanide VCN $\left(r_{1}\right)$ and Comonomers $M_{2}\left(r_{2}\right)$ in radical copolymerization. 


\section{FIGURE CAPTIONS}

Figure 1. IR spectra of poly(FAVE8) homopolymer (a), poly(VCN-alt-FAVE8) copolymer (b) and 1H,1H,2H,2H-perfluorodecyl vinyl ether (FAVE8) monomer (c).

Figure 2. Monomer/polymer composition curve from the radical copolymerization of VCN with FAVE8 (initiated by tertio-butyl peroxypivalate at $75^{\circ} \mathrm{C}$ ), calculated from elementary analysis. The full line represents the theoretical curve.

Figure 3. TGA thermograms of poly(VCN-alt-FAVE8) copolymer ( $\bullet$ (experiment \#6 in Table 1) poly(FAVE8) homopolymer $(\boldsymbol{\square})$ and poly $(\mathrm{VCN})$ homopolymer $(\boldsymbol{\Delta})$ under nitrogen.

Figure 4. a) Pictures of i) $(25 \mu \mathrm{m} \times 25 \mu \mathrm{m})$ water contact angles on the poly(VCN-alt-FAVE8) polymer film b) Water drop on the surface of the superhydrophobic film (the volume of the drop is $8 \mu \mathrm{l}$ ) and c) Scanning electron microscopy of the surface of this film.

Figure 5: Atomic Force microscopy picture of the surface of the poly(VCN-alt-FAVE-8) alternating copolymer (experiment 5, Table 1). 


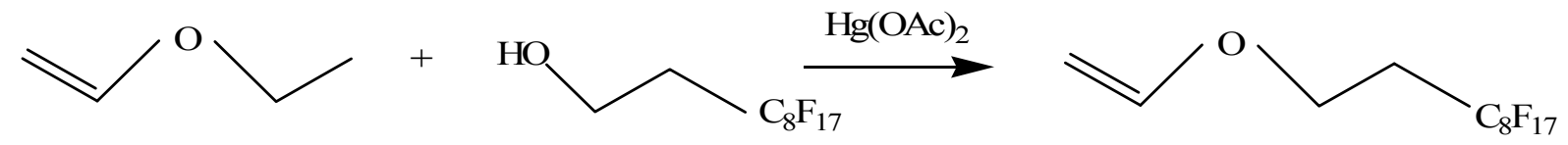

Scheme 1. Synthesis of 1H,1H,2H,2H-perfluorodecyl vinyl ether (FAVE8)

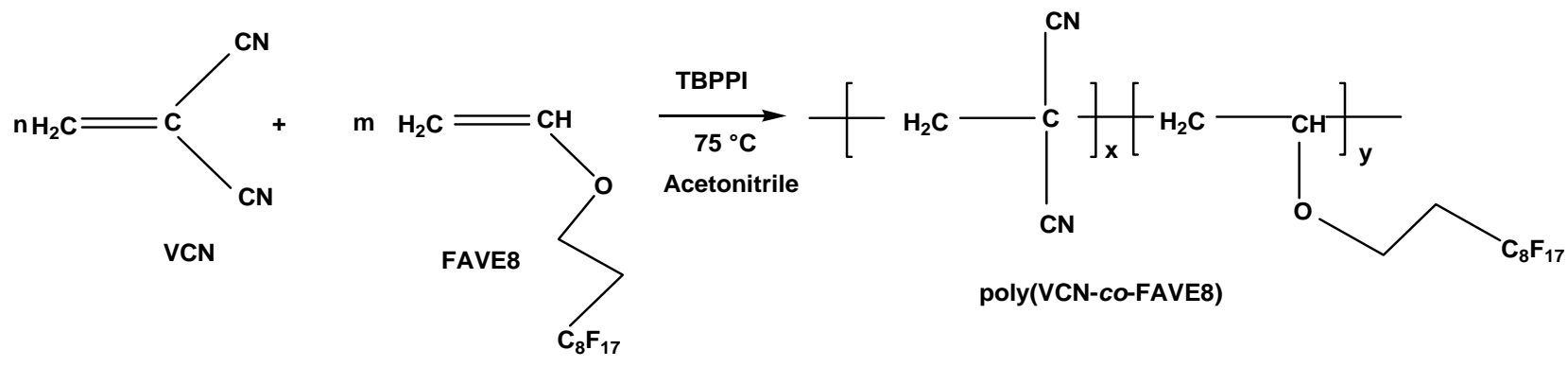

n<smiles>C=COCCC(F)F</smiles>

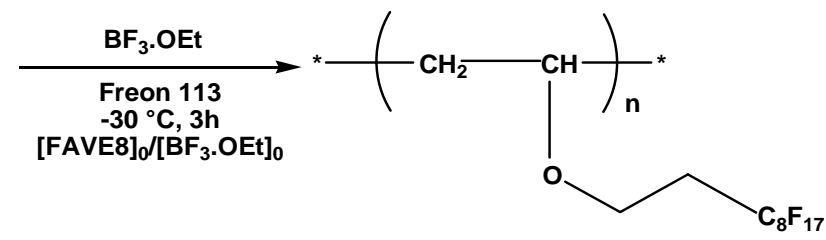

Scheme 2. (a) Radical copolymerization of Vinylidene cyanide (VCN) with $1 \mathrm{H}, 1 \mathrm{H}, 2 \mathrm{H}, 2 \mathrm{H}-$ perfluorodecyl vinyl ether (FAVE8) at $75{ }^{\circ} \mathrm{C}$ in acetonitrile, initiated with tertio-butyl peroxypivalate

(b) Cationic homopolymerization of FAVE8 initiated by $\mathrm{BF}_{3}$. Oet at $-30{ }^{\circ} \mathrm{C}$ in $1,1,2$-trichloro1,2,2-trifluoroethane. 


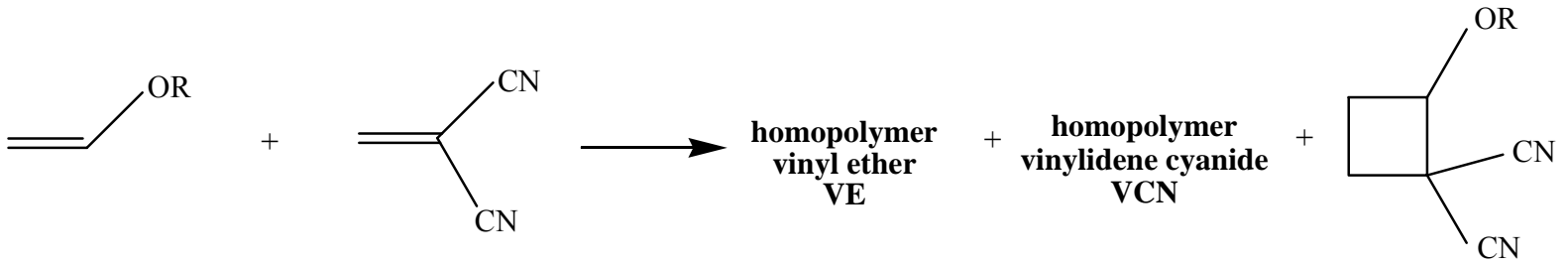

$\mathrm{R}=$ Alkyl group

Scheme 3. Different ways of reaction between a vinyl ether (VE) and vinylidene cyanide $(\mathrm{VCN})$ 


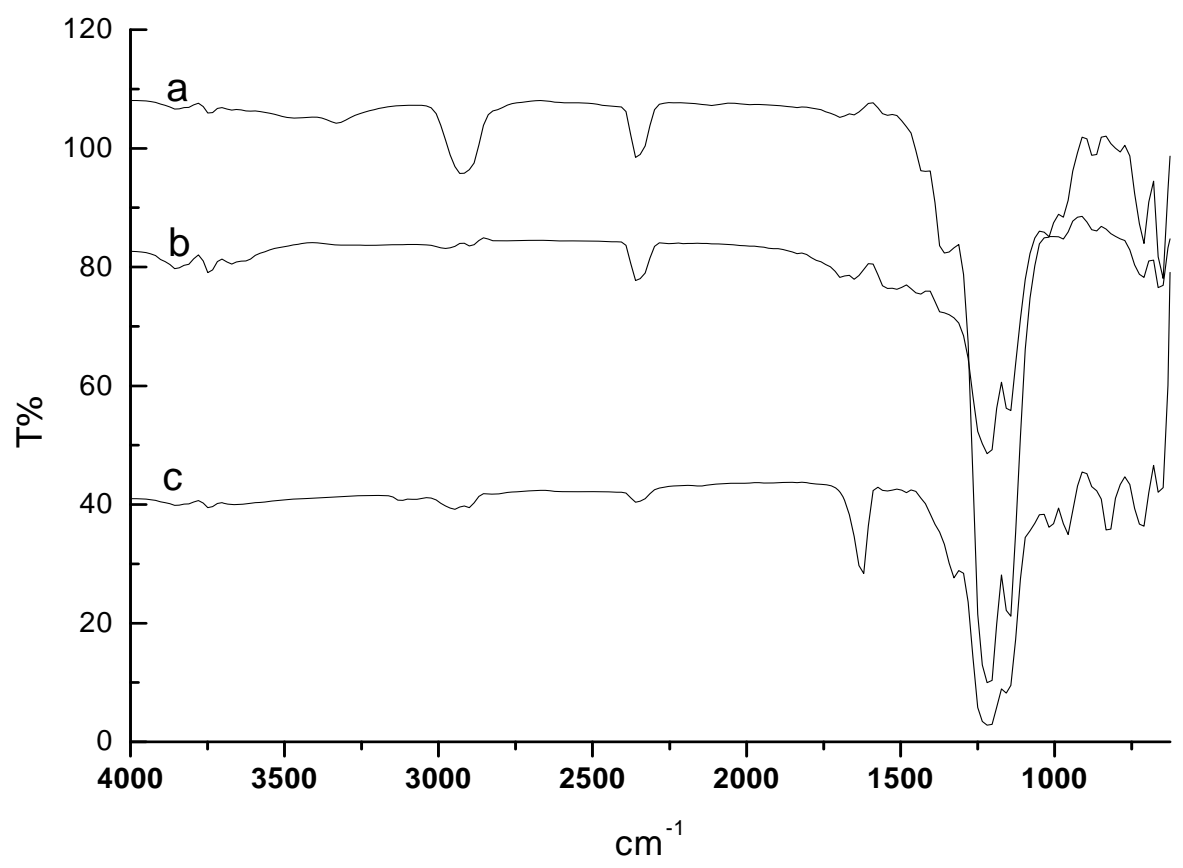

Figure 1. IR spectra of poly(FAVE8) homopolymer (a), poly(VCN-alt-FAVE8) copolymer (b) and $1 \mathrm{H}, 1 \mathrm{H}, 2 \mathrm{H}, 2 \mathrm{H}-$ perfluorodecyl vinyl ether (FAVE8) monomer (c) 


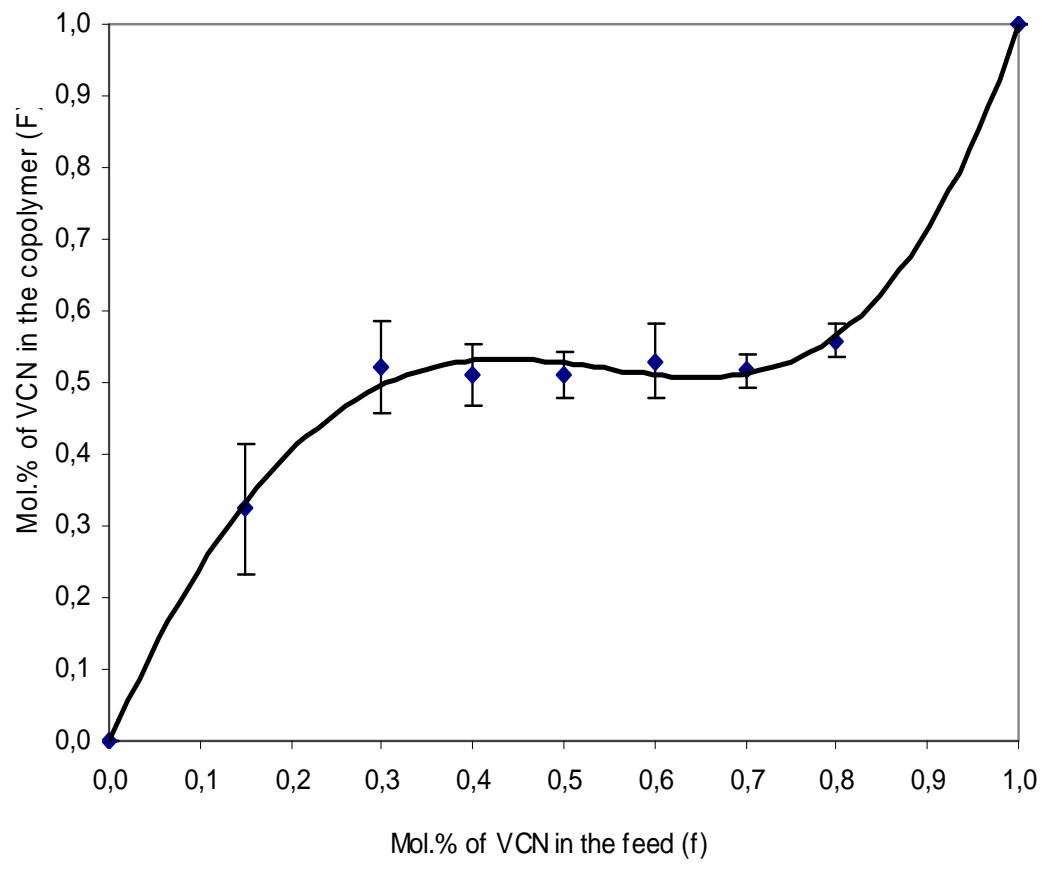

Figure 2. Monomer/polymer composition curve from the radical copolymerization of VCN with FAVE8 (initiated by tertio-butyl peroxypivalate at $75^{\circ} \mathrm{C}$ ), calculated from elementary analysis. The full line represents the theoretical curve. 


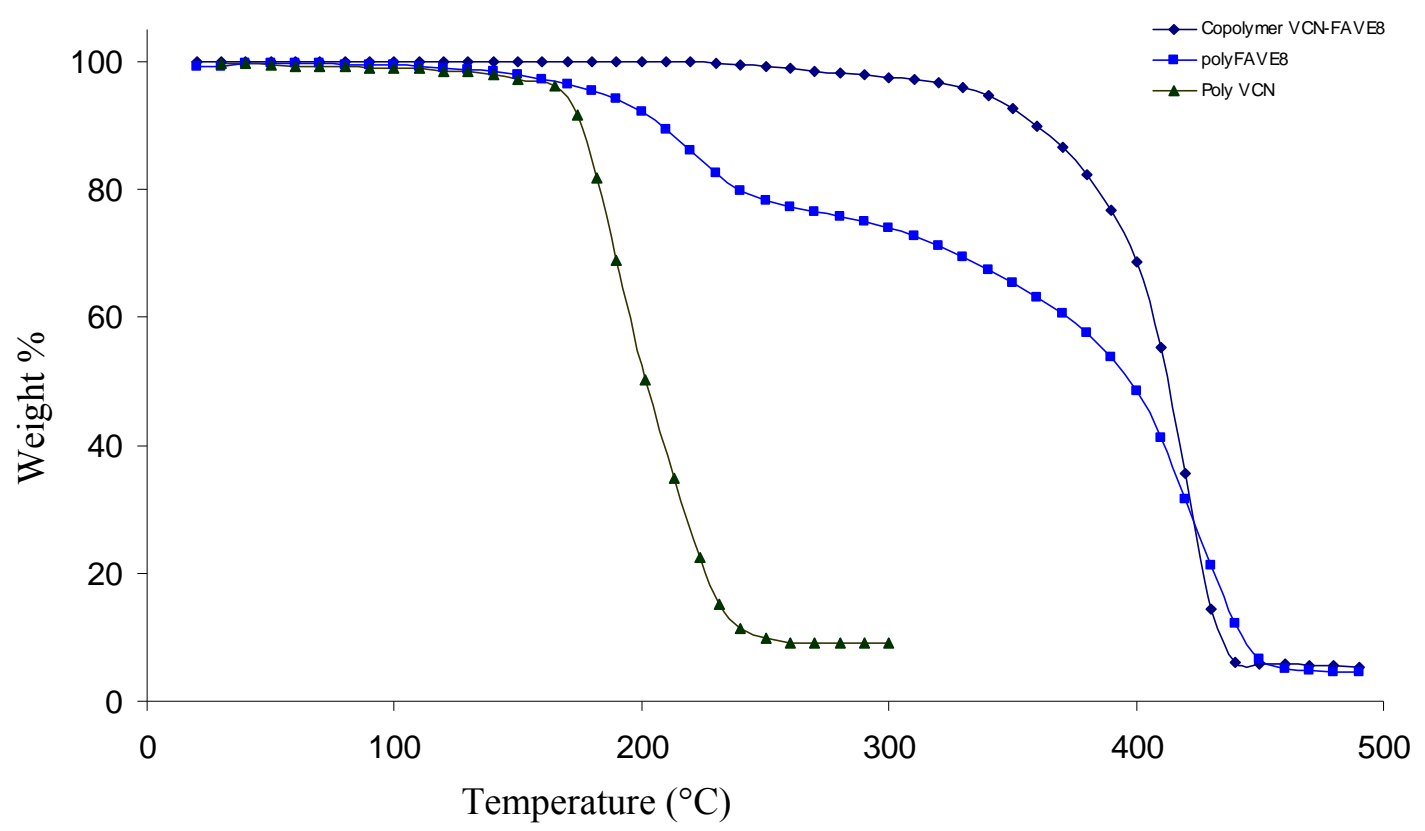

Figure 3. TGA thermograms of Poly(VCN-alt-FAVE8) copolymer $(\bullet)$ (experiment \#6 in Table 1); poly(FAVE8) homopolymer ( $\mathbf{\square})$; and poly(VCN) homopolymer ( $\mathbf{\Delta})$ under nitrogen. 


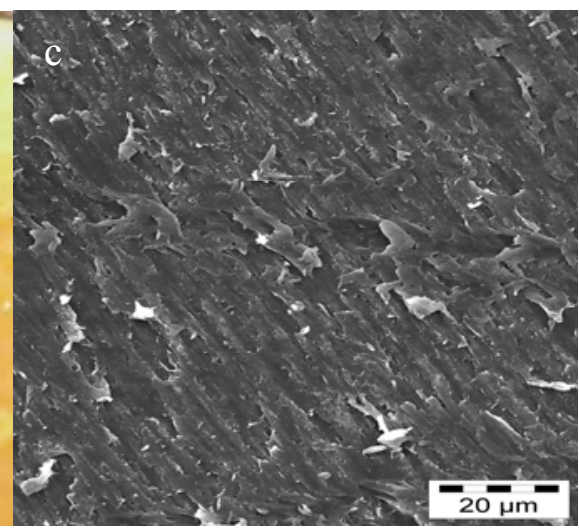

Figure 4: a) Pictures of i) $(25 \mu \mathrm{m} \times 25 \mu \mathrm{m})$ water contact angles on the poly(VCN-alt-FAVE8) polymer film b) Water drop on the surface of the superhydrophobic film (the volume of the drop is $8 \mu \mathrm{l}$ ) and c) Scanning electron microscopy of the surface of this film. 


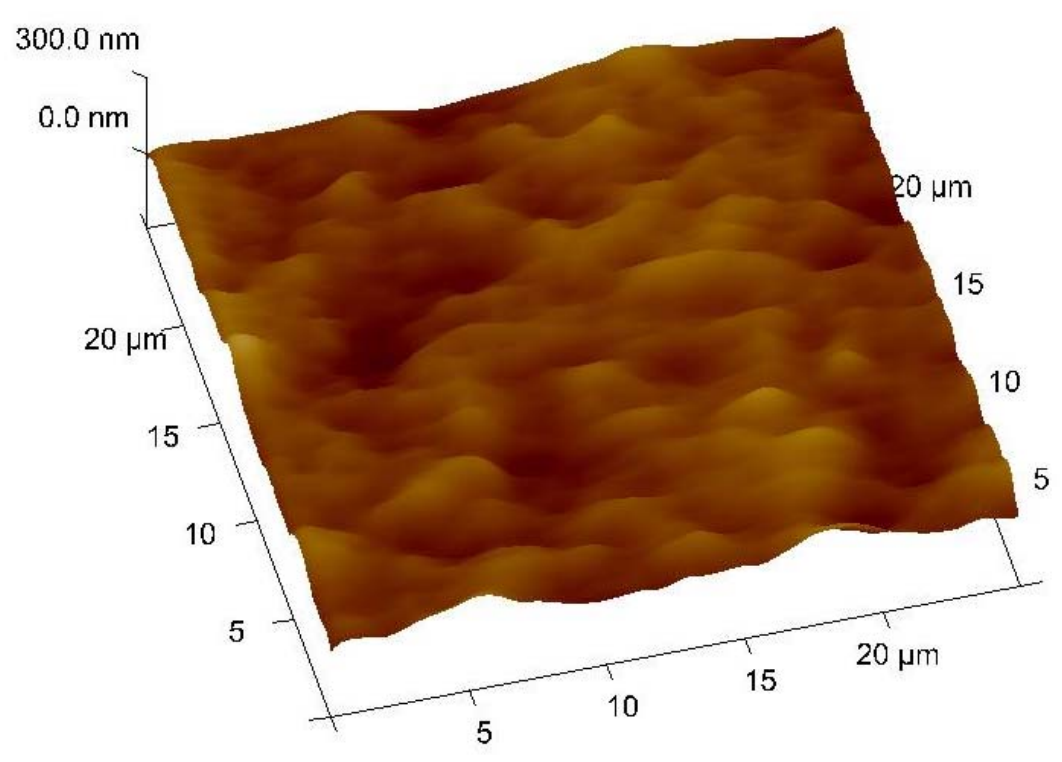

Figure 5. Atomic Force microscopy picture of the surface of the poly(VCN-alt-FAVE-8) alternating copolymer (experiment 5, Table 1). 
Table 1. Monomer/copolymer compositions from the kinetics of radical copolymerization of vinylidene cyanide (VCN) with 1H,1H,2H,2H-perfluorodecyl vinyl ether (FAVE8) determined by elemental analysis. Copolymerization conditions:

$[\mathrm{tBu}-\mathrm{OO}-\mathrm{CO}-\mathrm{tBu}]_{0} /\left([\mathrm{VCN}]_{0}+[\mathrm{FAVE} 8]_{0}\right)=1.5 \mathrm{~mol} . \%, 75{ }^{\circ} \mathrm{C}$ for $15 \mathrm{~min}$.

\begin{tabular}{|c|c|c|c|c|}
\hline \multirow{2}{*}{ Experiment \# } & \multirow{2}{*}{$\begin{array}{c}\text { VCN in feed } \\
(\mathrm{mol} . \%)\end{array}$} & \multicolumn{2}{|c|}{ Elementary analyses } & \multirow{2}{*}{$\begin{array}{c}\text { VCN in the copolymer } \\
(\mathrm{mol} . \%)\end{array}$} \\
\hline & & $\% \mathrm{~N}$ & $\% \mathrm{~F}$ & \\
\hline 1 & 15 & 1.65 & 59.23 & 32 \\
\hline 2 & 30 & 4.25 & 53.75 & 52 \\
\hline 3 & 40 & 4.41 & 54.99 & 51 \\
\hline 4 & 50 & 4.57 & 55.48 & 51 \\
\hline 5 & 60 & 4.59 & 53.99 & 53 \\
\hline 6 & 70 & 4.83 & 55.60 & 52 \\
\hline 7 & 80 & 5.56 & 54.02 & 56 \\
\hline
\end{tabular}

${ }^{a}$ Calculated from arithmetic mean of nitrogen and fluorine percentages 
Table 2. Fineman-Ross and Kelen-Tüdos parameters for the radical copolymerization of vinylidene cyanide (VCN) with $1 \mathrm{H}, 1 \mathrm{H}, 2 \mathrm{H}, 2 \mathrm{H}$-perfluorodecyl vinyl ether (FAVE8)

\begin{tabular}{|c|c|c|c|c|c|c|c|c|c|c|c|}
\hline & & $\mathrm{x}$ & & & $\mathrm{X}$ & & & $\mathrm{G}$ & $\mathrm{H}$ & $\eta$ & $\zeta$ \\
\hline$f_{\mathrm{VCN}}$ & $f_{\text {FAVE } 8}$ & $\frac{f_{V C N}}{f_{F A V E 8}}$ & $\mathrm{~F}_{\mathrm{VCN}}$ & $\mathrm{F}_{\mathrm{FAVE} 8}$ & $\frac{F_{V C N}}{F_{F A V E 8}}$ & $\mathrm{X} / \mathrm{x}^{2}$ & $(\mathrm{X}-1) / \mathrm{x}$ & $\mathrm{x}(\mathrm{X}-1) / \mathrm{X}$ & $\mathrm{x}^{2} / \mathrm{X}$ & $\mathrm{G} /(\mathrm{H}+\alpha)$ & $\mathrm{H} /(\mathrm{H}+\alpha)$ \\
\hline 0.15 & 0.85 & 0.176 & 0.320 & 0.680 & 0.471 & 15.111 & 3.000 & 0.199 & 0.066 & -0.202 & 0.067 \\
\hline 0.30 & 0.70 & 0.429 & 0.522 & 0.478 & 1.094 & 5.954 & 0.219 & 0.037 & 0.168 & 0.034 & 0.155 \\
\hline 0.40 & 0.60 & 0.937 & 0.512 & 0.488 & 1.048 & 1.193 & 0.051 & 0.043 & 0.839 & 0.024 & 0.478 \\
\hline 0.50 & 0.50 & 1.000 & 0.510 & 0.490 & 1.041 & 1.041 & 0.041 & 0.039 & 0.961 & 0.021 & 0.512 \\
\hline 0.60 & 0.40 & 1.500 & 0.530 & 0.470 & 1.129 & 0.502 & 0.086 & 0.172 & 1.993 & 0.059 & 0.685 \\
\hline 0.70 & 0.30 & 2.333 & 0.516 & 0.484 & 1.067 & 0.196 & 0.029 & 0.146 & 5.103 & 0.024 & 0.848 \\
\hline 0.80 & 0.20 & 4.000 & 0.558 & 0.442 & 1.262 & 0.079 & 0.065 & 0.829 & 12.683 & 0.061 & 0.933 \\
\hline
\end{tabular}


Table 3. Reactivity ratios of vinylidene cyanide, $\mathrm{VCN}\left(\mathrm{r}_{12}\right)$ and comonomers $\mathrm{M}_{2}\left(\mathrm{r}_{21}\right)$ in radical copolymerization

\begin{tabular}{llllll}
\hline $\mathrm{M}_{2}$ & $\mathrm{r}_{12}$ & $\mathrm{r}_{21}$ & $\mathrm{r}_{12} \mathrm{Xr}_{21}$ & $1 / \mathrm{r}_{12}$ & Ref \\
\hline Styrene & 0.001 & 0.003 & $3.0 \times 10^{-6}$ & 1000 & 62 \\
2,5-dichlorostyrene & 0.0092 & 0.031 & $2.8 \times 10^{-4}$ & 109 & 4 \\
a-acetoxystyrene & 0.125 & 0.010 & $1.3 \times 10^{-3}$ & 8 & 17 \\
cis-dichloroethylene & 30 & 0 & 0 & 0.034 & 5 \\
trans-dichloroethylene & 30 & 0 & 0 & 0.034 & 5 \\
Vinylidene chloride & 0.049 & 0.012 & $5.9 \times 10^{-4}$ & 20 & 5 \\
Vinyl chloride & 0.540 & 0.017 & $9.2 \times 10^{-3}$ & 2 & 5 \\
Vinyl benzoate & 0.100 & 0.008 & $8.0 \times 10^{-4}$ & 10 & 5,11 \\
Vinyl acetate & 0.111 & 0.005 & $5.9 \times 10^{-4}$ & 9 & 5 \\
Vinyl chloroacetate & 0.130 & 0 & 0 & 7.7 & 4,5 \\
Methyl methacrylate & 0.031 & 0.046 & $1.4 \times 10^{-3}$ & 32 & 5,12 \\
Methyl $\alpha$-chloroacrylate & 0.091 & 0.410 & $3.7 \times 10^{-2}$ & 11 & 4,5 \\
Methyl $\alpha$-acetoxyacrylate & 0.100 & 0.370 & $3.7 \times 10^{-2}$ & 10 & 66 \\
Ethyl $\alpha$-acetoxyacrylate & 0.200 & 0.130 & $2.6 \times 10^{-2}$ & 5 & 67 \\
Acrylic acid & 0.290 & 0.260 & $7.5 \times 10^{-2}$ & 3.5 & 4 \\
FAVE8 & 0.08 & 0.070 & $5.0 \times 10^{-3}$ & 12.5 & This work \\
FAVE8 & 0.0027 & 0.0000 & $1.1 \times 10^{-8}$ & 370 & This work \\
2-chloroproprene & 0.2 & 0.001 & $2.0 \times 10^{-4}$ & 5 & 5 \\
2-chloro-1,3-butadiene & 0.0048 & 0.016 & $7.7 \times 10^{-5}$ & 208 & 4 \\
\hline & & 0.5 & & 5 \\
\hline
\end{tabular}

${ }^{a}$ arithmetic average from Fineman and $\operatorname{Ross}^{53}$ and Kelen and Tüdos ${ }^{54}$

${ }^{\mathrm{b}}$ from the Revised Patterns A,S Scheme ${ }^{55-59}$ 


\title{
TABLE of CONTENTS
}

\section{Unexpected Alternated Radical Copolymerization of Vinylidene cyanide with a Vinyl ether for Superhydrophobic and Highly Oleophobic Films}

\begin{abstract}
Ahmed Meskini, Mustapha Raihane
Laboratoire de Chimie Bioorganique et Macromoléculaire - Faculté des Sciences et Techniques - Avenue Abdelkrim Khattabi - BP 549, 40000 Marrakech (Morocco)

\section{Bruno Ameduri*}

Engineering and Macromolecular Architectures, Institut Charles Gerhardt - UMR (CNRS) 5253- Ecole Nationale Supérieure de Chimie de Montpellier - 8 Rue Ecole Normale, 34296 Montpellier Cedex 5 (France)
\end{abstract}

\begin{tabular}{|l|l|l|l|} 
Unexpected Alternated & Radical Copolymerization \\
of Vinylidene cyanide with \\
a F-Vinyl ether for \\
Superhydrophobic and \\
Highly Oleophobic Films \\
Ahmed Meskini, Mustapha \\
Raihane, Bruno Ameduri
\end{tabular}


